\title{
Clinical Features of Colorectal Cancer Detected by the National Cancer Screening Program
}

\author{
Dae-Do Park, Rumi Shin, Ji-Sun Kim, Heung-Kwon Oh, Seung-Yong Jeong, Kyu Joo Park, Jae-Gahb Park \\ Department of Surgery, Seoul National University College of Medicine, Seoul, Korea
}

Purpose: Since 2004, the National Cancer Screening Program of Korea has included colorectal cancer screening based on primary screening with the fecal occult blood test (FOBT). We report on the clinical features of colorectal cancer detected by the National Cancer Screening Program.

Methods: We retrospectively analyzed 577 patients who underwent elective surgery for colorectal cancer at the Seoul National University Hospital between January 2008 and December 2009. We compared the clinical features of colorectal cancers detected by the National Cancer Screening Program (NCSP group) with those of the control group in terms of age, gender, preoperative symptom, location of the tumor, surgical technique and tumor-node-metastasis (TNM) stage.

Results: Age, gender, location of the tumor and operation types were not different between the two groups. The proportion of asymptomatic patients was significantly higher in the NCSP group than it was in the control group (86.5\% vs. $20.0 \%$; P $<0.001$ ). The proportion of less invasive lesions (T1 or T2) was significantly higher in the NCSP group $(46.3 \%$ vs. $27.7 \% ; \mathrm{P}=0.002$ ). The pathologic stages of the colorectal cancers in the NCSP group were I, $40.3 \%$; II, $17.9 \%$; III, $40.3 \%$ and IV, $1.5 \%$ whereas in the control group, they were I, $20.8 \%$; II, $32.9 \%$; III, 34.9\% and IV, $11.4 \%$. The proportion of stage I cancer was significantly higher in the NCSP group than in the control group $(40.3 \%$ vs. $20.8 \%$; $\mathrm{P}=0.006)$. Conclusion: Our study demonstrates the FOBT in the NCSP is effective in early detection of colorectal cancer.

\section{Keywords: FOBT; National Cancer Screening Program}

\section{INTRODUCTION}

According to the National Cancer Registry Data reported by the National Cancer Information Center, colorectal cancer (CRC) occurs in 33 persons out of 100 thousand in Korea and ranks third following stomach cancer and thyroid cancer in terms of the incidence rate, and its incidence rate is currently skyrocketing [1-4]. In addition, although the five-year survival rate for colorectal cancer occurring from 2003 to 2007 has been recorded as $68.7 \%$, the survival rate has dropped sharply

Received: August 31, 2010 Accepted: September 16, 2010

Correspondence to: Jae-Gahb Park, M.D.

Department of Surgery, Seoul National University College of Medicine,

Yeongeon-dong, Jongno-gu, Seoul 110-799, Korea

Tel: +82-2-2072-3380, Fax: +82-2-766-3975

E-mail: jgpark@plaza.snu.ac.kr

(C) 2010 The Korean Society of Coloproctology

This is an open-access article distributed under the terms of the Creative Commons Attribution NonCommercial License (http://creativecommons.org/licenses/by-nc/3.0) which permits unrestricted noncommercial use, distribution, and reproduction in any medium, provided the original work is properly cited. with the progression of stages as the rates of stage I and stage IV cancer are over $90 \%$ and less than 5\%, respectively. Therefore, to reduce the mortality rate caused by colorectal cancer, early detection is a prerequisite [4-6]. Screening tests for early detection of colorectal cancer are the fecal occult blood test (FOBT), sigmoidoscopy, colonoscopy, and double-contrast barium enema, and a large-scale case control study using FOBT revealed that the mortality rate due to colorectal cancer was decreased by $16 \%$ in the group participating in the screening [7-10].

In Korea, the "Cancer Control Plan for the Next 10 Years" was implemented in 1996, and the second-term "Cancer Control Plan for the Next 10 Years" has been operating since 2006. As a plan of action, the National Cancer Screening Program (NCSP) has been ongoing since 1999, and the program has included CRC screening since 2004. For this, medical aid recipients and national health insurance beneficiaries older than 50 years take the FOBT every year, and when the result is positive, they take confirmative tests, 'colonoscopy' or 'double-contrast barium enema' [11] (Fig. 1). To date, however, data on 
improved screening and survival rates due to the FOBT have not been reported. Therefore, this study investigated the clinical characteristics of colorectal cancer detected by the FOBT performed in the NCSP to provide basic data on screening of colorectal cancer and to help to decide future directions for the NCSP.

\section{METHODS}

From January 2008 to December 2009, 588 patients underwent elective surgery for CRC at Seoul National University Hospital. We excluded 11 patients who had undergone surgery due to colorectal cancer or who had been diagnosed with familial adenomatous polyposis or hereditary non-polyposis colorectal cancer; the remaining 577 patients were included for analysis. We divided these patients into two groups; the NCSP group (n $=67$ ) whose CRCs were diagnosed by using the NCSP, and the control group $(n=510)$. Demographic and clinicopathologic characteristics of the patients were compared between the groups. All statistical analyses were conducted with SPSS ver. 17.0 (SPSS Inc., Chicago, IL, USA) for Windows, and the chisquared test or the independent sample t-test was utilized. A P-value of less than 0.05 was considered to be statistically significant.

\section{RESULTS}

\section{Age and gender}

The mean age of the 577 subjects was $61.6 \pm 11.4$ years (range, 22 to 91 years), and the mean age of the NCSP group was significantly higher than that of the control group $(64.5 \pm 6.6$ years [range, 50 to 80 years] vs. $61.2 \pm 11.8$ years [range, 22 to 91 years], respectively, $\mathrm{P}=0.001)$. Of the total subjects, $356(61.7 \%)$ and $221(38.3 \%)$ were males and females, respectively, for a ratio of 1.6:1. The male-to-female ratios of the NCSP group and the control group were 1.9:1, with 44 (65.7\%) males and $23(34.3 \%)$ females, and 1.6:1, with 312 (61.2\%) males and 198 (38.8\%) females, respectively, and this difference was not statistically significant $(\mathrm{P}=0.477)$ (Table 1$)$.

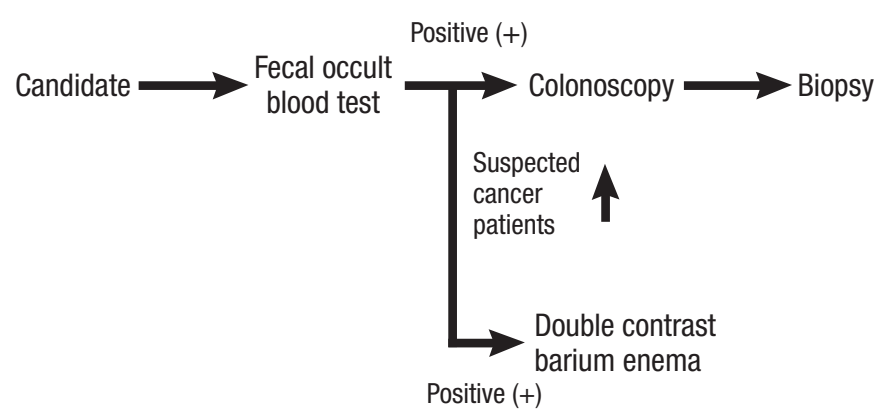

Fig. 1. Colorectal cancer screening procedure.

\section{Preoperative symptoms}

In the NCSP group, as preoperative symptoms, no symptoms, hematochezia, abdominal pain, change of bowel habit and dyspepsia were found in $58(86.5 \%), 5(7.5 \%), 2(3 \%), 1(1.5 \%)$ and $1(1.5 \%)$ cases, respectively. In the control group, hematochezia, changes of bowel habit, no symptoms, abdominal pain, dyspepsia and other symptoms were found in 183 (35.9\%), 105 (20.6\%), $102(20.0 \%), 85$ (16.6\%), 11 (2.2\%) and 24 (4.7\%) cases, respectively. Asymptomatic patients accounted for the largest portion in the NCSP group while hematochezia was the main symptom in the control group $(\mathrm{P}<0.001)$.

\section{Location of tumors}

The location of the tumor was classified as the ascending colon, the transverse colon, the descending colon, the sigmoid colon and the rectum. For the NCSP group, the tumors were located in the ascending colon, the transverse colon, the descending colon, the sigmoid colon and the rectum in $14(20.9 \%), 3(4.5 \%)$, $1(1.5 \%), 22(32.8 \%)$ and $27(40.3 \%)$ patients, respectively, so rectal cancer was observed most frequently. For the control group, the tumors were located in the ascending colon, the transverse colon, the descending colon, the sigmoid colon and the rectum in 70 (13.7\%), 46 (9.0\%), 10 (2.0\%), 159 (31.2\%) and $225(44.1 \%)$ patients, respectively. The distributions were not significantly different between the two groups $(\mathrm{P}=0.400)$.

\section{Surgical treatments}

In both the NCSP group and the control group, a low anterior resection was conducted most frequently, and the surgical treatments of the two groups did not show any statistically significant difference $(\mathrm{P}=0.069)$ (Table 2 ).

\section{Histopathologic staging (TNM staging)}

The rates of $\mathrm{T} 1$ and $\mathrm{T} 2$ cancers were relatively higher in the NCSP group (46.3\%) than in the control group (27.7\%), and the rate of stage I was also higher in the NCSP group $(40.3 \%)$ than in the control group $(20.8 \%)$ The rate of N0 cancer in the NCSP group was higher than that in the control group, but the difference was not statistically significant (Table 3).

\section{DISCUSSION}

Cancer screening for persons aged 50 and over through the

Table 1. Distribution of age and gender

\begin{tabular}{lccc}
\hline & $\begin{array}{c}\text { NCSP group } \\
(\mathrm{n}=67)\end{array}$ & $\begin{array}{c}\text { Control group } \\
(\mathrm{n}=510)\end{array}$ & P-value \\
\hline Mean age $(\mathrm{yr})$ & $64.48( \pm 6.60)$ & $61.19( \pm 11.88)$ & $<0.01$ \\
$\begin{array}{l}\text { Male:Female } \\
(\%)\end{array}$ & $44: 23$ & $312: 198$ & 0.477 \\
\hline
\end{tabular}

NCSP, National Cancer Screening Program. 
Table 2. Distribution of surgical treatment

\begin{tabular}{lll}
\hline & \multicolumn{1}{c}{$\operatorname{NCSP}$ group $(n=67)$} & \multicolumn{1}{c}{ Control group $(n=510)$} \\
\hline Surgical treatment & Right hemicolectomy $(16,23.9)$ & Right hemicolectomy $(104,20.4)$ \\
& Left hemicolectomy $(1,1.5)$ & Left hemicolectomy $(18,3.5)$ \\
& Anterior resection $(22,32.8)$ & Anterior resection $(135,26.5)$ \\
& $\operatorname{LAR}(23,34.3)$ & $\operatorname{LAR}(67,32.7)$ \\
& $\operatorname{ULAR}(4,6.0)$ & $\operatorname{ULAR}(57,11.2)$ \\
& Subtotal colectomy $(1,1.5)$ & Others ${ }^{\text {a }}(29,5.7)$ \\
\hline
\end{tabular}

Values are presented as number, $\%$.

LAR, low anterior resection; ULAR, ultralow anterior resection.

aSubtotal colectomy, 6; total colectomy, 4; abdominoperineal resection, 5; Hartmann's operation, 3; stomy, 7 (colostomy, 5; ileostomy, 2); transanal excision, 4.

Table 3. Distribution of histopathologic stage (TNM stage)

\begin{tabular}{lccc}
\hline & $\begin{array}{c}\text { NCSP group } \\
(\mathrm{n}=67)\end{array}$ & $\begin{array}{c}\text { Control group } \\
(\mathrm{n}=510)\end{array}$ & P-value \\
\hline T-stage & & & 0.002 \\
T1 & $16(23.9)$ & $56(11.2)$ & \\
T2 & $15(22.4)$ & $82(16.5)$ & \\
T3 & $33(49.2)$ & $312(62.7)$ & \\
T4 & $3(4.5)$ & $48(9.6)$ & \\
N-stage & & & 0.077 \\
N0 & $40(59.7)$ & $293(57.5)$ & \\
N1 & $22(32.8)$ & $123(24.1)$ & \\
N2 & $5(7.5)$ & $83(16.3)$ & \\
Nx & $0(0)$ & $11(2.1)$ & \\
M-stage & & & 0.009 \\
M0 & $66(98.5)$ & $452(88.6)$ & \\
M1 & $1(1.5)$ & $58(11.4)$ & \\
TNM-stage & & & \\
I & $27(40.3)$ & $106(20.8)$ & \\
II & $12(17.9)$ & $168(32.9)$ & \\
III & $27(40.3)$ & $178(34.9)$ & \\
IV & $1(1.5)$ & $58(11.4)$ & \\
\hline
\end{tabular}

Values are presented as number (\%).

NCSP, National Cancer Screening Program; TNM, tumor-node-metastasis.

FOBT, sigmoidoscopy, colonoscopy and double-contrast barium enema is well known to be important because early detection of CRC can improve the survival and the quality of life of patients [12]. Out of the screening tests, the FOBT is effective, cheap and less invasive [13]. However, while the FOBT produces no complications and is cheap and simple, additional tests are necessary due to its low sensitivity, low positive predictive value, and high false positive rate [14-16]. In addition, the National Polyp Study in the US reported that when persons who were normal in colonoscopy or whose polyps were removed by using a polypectomy were followed for six years, the incidence rate of CRC was reduced by 76-90\% [17]. Thus, applying colonoscopy to all examinees can enhance detection rate; nevertheless, its use is limited to an additional test for persons with abnormal results on the FOBT because it is relatively expensive, can lead to serious complications, such as colonic perforation, although it is rarely found, provokes discomfort in examinees and requires skilled endoscopy specialists, who are not available in sufficient numbers $[13,18,19]$.

In this study, while the rates of $\mathrm{T} 1$ and $\mathrm{T} 2$ cancers and stage I cancer were relatively higher in the NCSP group than in the control group, the rate of stage IV cancer in the NCSP group (only one patient, 1.5\%) was relatively low compared to that in the control group. Paimela et al. [20] also reported that the rates of stage I and II cancers were higher in the FOBT screening group (52\%) than in the control group (38\%) in their study conducted with around 100 thousand subjects from 2004 to 2006. That meant that CRC was detected earlier in the FOBT screening group than in the control group. This study found no significant difference in $\mathrm{N}$ staging between the two groups, and the reason is thought to be the small number of subjects.

The patients of the NCSP group (64.5 years) were observed to be older than those of the control group (61.6 years). That was considered to be because the recipients of the National Cancer Screening Program were over 50 years of age and did not include young patients.

This study is limited in demonstrating the exact effects of the screening because of the possibility of including patients who had undergone CRC screening outside the tract of the NCSP in the control group and including symptomatic patients at the time of screening in the NCSP group. However, because only few data on the CRC screening using the FOBT performed as a part of the NCSP are available, the results of this study are meaningful as basic data. Moreover, the finding that the rate of detection of cancer in its early stage was significantly higher in the national cancer screening group than in the control group carries an important meaning.

The CRC patients whose tumors were detected through the National Cancer Screening Program by using the FOBT showed a higher proportion of early stage lesions, which implies that the current National Cancer Screening Program in Korea contributes to early detection of colorectal cancer. 


\section{CONFLICT OF INTEREST}

No potential conflict of interest relevant to this article was reported.

\section{REFERENCES}

1. Wilmink AB. Overview of the epidemiology of colorectal cancer. Dis Colon Rectum 1997;40:483-93.

2. Shin HR, Won YJ, Jung KW, Kong HJ, Yim SH, Lee JK, et al. Nationwide cancer incidence in Korea, 1999-2001: first result using the national cancer incidence database. Cancer Res Treat 2005; 37:325-31.

3. Park YJ, Youk EG, Choi HS, Han SU, Park KJ, Lee KU, et al. Experience of 1446 rectal cancer patients in Korea and analysis of prognostic factors. Int J Colorectal Dis 1999;14:101-6.

4. 2007 Annual Report of the National Cancer Registry 2010 [Internet]. Goyang: National Cancer Center; [cited 2010 Jan 5]. Available from: http://ncc.re.kr/common/downloadByNTC. jsp?attnum $=193 \&$ code $=999$ _101.

5. Citarda F, Tomaselli G, Capocaccia R, Barcherini S, Crespi M; Italian Multicentre Study Group. Efficacy in standard clinical practice of colonoscopic polypectomy in reducing colorectal cancer incidence. Gut 2001;48:812-5.

6. Mandel JS, Church TR, Bond JH, Ederer F, Geisser MS, Mongin SJ, et al. The effect of fecal occult-blood screening on the incidence of colorectal cancer. N Engl J Med 2000;343:1603-7.

7. Mandel JS, Bond JH, Church TR, Snover DC, Bradley GM, Schuman LM, et al. Reducing mortality from colorectal cancer by screening for fecal occult blood. Minnesota Colon Cancer Control Study. N Engl J Med 1993;328:1365-71.

8. Kronborg O, Fenger C, Olsen J, Jorgensen OD, Sondergaard O. Randomised study of screening for colorectal cancer with faecaloccult-blood test. Lancet 1996;348:1467-71.

9. Hardcastle JD, Chamberlain JO, Robinson MH, Moss SM, Amar SS, Balfour TW, et al. Randomised controlled trial of faecal-occult- blood screening for colorectal cancer. Lancet 1996;348:1472-7.

10. Kewenter J, Brevinge H, Engaras B, Haglind E, Ahren C. Followup after screening for colorectal neoplasms with fecal occult blood testing in a controlled trial. Dis Colon Rectum 1994;37:115-9.

11. National Cancer Information Center. National Cancer Screening Program [Internet]. Goyang: National Cancer Center; [cited 2010 Apr 30]. Available from: http://www.cancer.go.kr/cms/public_ project/inspection/index.html.

12. Rex DK, Johnson DA, Lieberman DA, Burt RW, Sonnenberg A. Colorectal cancer prevention 2000: screening recommendations of the American College of Gastroenterology. American College of Gastroenterology. Am J Gastroenterol 2000;95:868-77.

13. Vijan S, Hwang EW, Hofer TP, Hayward RA. Which colon cancer screening test? A comparison of costs, effectiveness, and compliance. Am J Med 2001;111:593-601.

14. Sohn DK, Jeong SY, Choi HS, Lim SB, Huh JM, Kim DH, et al. Single immunochemical fecal occult blood test for detection of colorectal neoplasia. Cancer Res Treat 2005;37:20-3.

15. Helm J, Choi J, Sutphen R, Barthel JS, Albrecht TL, Chirikos TN. Current and evolving strategies for colorectal cancer screening. Cancer Control 2003;10:193-204.

16. Hewitson P, Glasziou P, Irwig L, Towler B, Watson E. Screening for colorectal cancer using the faecal occult blood test, Hemoccult. Cochrane Database Syst Rev 2007;(1):CD001216.

17. Winawer SJ, Zauber AG, Ho MN, O'Brien MJ, Gottlieb LS, Sternberg SS, et al. Prevention of colorectal cancer by colonoscopic polypectomy: the National Polyp Study Workgroup. N Engl J Med 1993;329:1977-81.

18. Ransohoff DF, Lang CA. Using colonoscopy to screen for colorectal cancer. Am J Gastroenterol 1994;89:1765-6.

19. Woolf SH. The best screening test for colorectal cancer--a personal choice. N Engl J Med 2000;343:1641-3.

20. Paimela H, Malila N, Palva T, Hakulinen T, Vertio H, Jarvinen H. Early detection of colorectal cancer with faecal occult blood test screening. Br J Surg 2010;97:1567-71. 